\title{
Microbial Isolates from Patients and their Antibiogram at the Tertiary care Burn Unit in Bangladesh
}

\author{
H BEGUM $^{\mathrm{a}}$, M QUAMRUZZAMAN ${ }^{\mathrm{b}}, \mathrm{M}^{\mathrm{T}} \mathrm{TLULNDAR}^{\mathrm{c}}$
}

\begin{abstract}
Summary
Infection and antibacterial resistance are important issue in severe burn. This prospective study was carried out in 112 patients who were enrolled from July 2007 to June 2008 in DMCH burn unit (only dedicated burn facility in Bangladesh with a mean annual admission of 869). The aim of this study were to investigate the profile of microorganism and resistance to antimicrobial agents; individuals who were admitted more than 5 days, with partial or full thickness burn developed clinical signs and symptoms of wound infection or pneumonia or septicaemia were included in this study. Nearly $50 \%$ of participants were aged 11-30 yrs, the most common type of burn was flame burn and females were the common victims. Bacterial isolates were found in 104 (92.85\%) samples and eight (08) swabs
\end{abstract}

\section{Introduction:}

Burn wounds are never sterile, even in the presence of topical agents or systemic antibiotics. ${ }^{1}$ Severe burn caused complex changes in homeostasis that can hardly be compared with other traumas or disorders and mortality is relatively common in the early phase. Infection is an important cause of mortality in burn, if the burn exceeds $40 \%$ of the total body surface area (TBSA). Wound infection will be one of the main complications $^{2}$. Sepsis is the leading cause of death in patient with large burns. ${ }^{3} 75 \%$ of all deaths following burn injury are related to infection ${ }^{4}$. Infection in the wound prolongs the healing process; treatment includes

a. Dr. Hasina Begum, DA, FCPS (Anaesthesiology), Junior Consultant, 50 Bedded Burn Unit, DMCH.

b. Dr. Muhammad Quamruzzaman, FCPS (Surgery); MS (Plastic Surgery), Assistant Professor (Plastic Surgery), 50 Bedded Burn Unit, DMCH.

c. Dr. Moumita Talukdar, DA, MCPS (Anaesthesiology), Medical Officer, 50 Bedded Burn Unit, DMCH.

Address of Correspondence : Dr. Hasina Begum, DA, FCPS (Anaesthesiology), Junior Consultant, 50 Bedded Burn Unit, DMCH. Received : 23 September, 2008

Accepted : 18 October, 2010 were sterile (7.14\%). Pseudomonas species was the commonest pathogens (46.42\%) followed by Proteus species (21.41\%) and Klebsiella species (19.6\%). Multiple organisms were found in 38 samples(33.92\%). Antibiogram results obtained from ten antimicrobial agents demonstrated that Imipenem was the most efective agent, followed by amikacin and ceftazidime (92.3\%, 52.8\% and $38.46 \%$ sensitive respectively). Hundred percent (100\%) of Proteus species were sensitive to imipenem, then amikacin $58.33 \%$; they were highly resistant to cephalosporins (nearly 100\%) and ciprofloxacin (83.33\%). The resistance of Pseudomonas aeruginosa to anti-pseudomonas agents were exceptionally high. Newer drugs were found to be effective.

(J Bangladesh Coll Phys Surg 2011; 29: 62-66)

rational antibiotic administration, removal of necrotic tissues, sufficient blood and oxygen supply to the wound and good nutritional support in burn victims. ${ }^{5}$ Individual hospital units will notice a change in their common pathogens over time. Infetions with Pseudomonas organisms began to be seen in increasing numbers. ${ }^{6}$ From $11 \%$ to $30 \%$ of burns are contaminated by microorganism of the gastrointestinal tract, skin and upper respiratory system, including Pseudomonas aeruginosa, Staphylocoocus aureus, Escherichia coli, Klebsiella spp, Enterococcus spp and Candida spp. ${ }^{7}$ The organism most often involved in wound infection particularly in the first week is Staphylocoocus aureus. ${ }^{8}$ Infection with gram-negative organism is more evident after the $1^{\text {st }}$ week. Pseudomonas organism is present on the wounds of approximately $25 \%$ of burn patients. ${ }^{1}$ Enterococci and Candida albicans are now seen with increasing frequency, each being found in the wounds of about $50 \%$ of burn patients ${ }^{1}$. The rate of nosocomial infections are higher in burn patients due to various factors like nature of burn injury itself, immunocompromised status of the patients, invasive diagnostic and therapeutic procedures and prolonged ICU stay. In addition, cross-infection results between 
different burn patients due to overcrowding in burn wards. Antimicrobial resistance is a great problem in infectious disease. In burn units, because of the wide use of antibiotics and particularly the empirical administration of broad-spectrum antimicrobial, this problem is worse than in other hospital department. ${ }^{9}$ Complicating this high rate of infection is the fact that the spectrum of bacterial isolate varies with time and geographical area. ${ }^{10}$

The present prospective study was conducted to determine the bacteriological profile and the resistance pattern in the burn unit of $\mathrm{DMCH}$, a tertiary referral center, Bangladesh, which forms the basis for modification of drug regimen strategy.

\section{Material and Methods:}

This prospective cross-sectional study involved 112 patients who were enrolled from July 2007 to June 2008 in burn unit, DMCH, which is the only dedicated burn facility in Bangladesh with a mean annual admission of about 869. It receives all severe burn cases and more than $90 \%$ of burn cases in Bangladesh.

Early excision and skin grafting is practiced in our unit as soon as the patients are surgically fit and repeated till all areas of the body are grafted. Superficial burns not requiring surgery are dressed with duoderm to permit moist wound healing. Extent and severity of burns are calculated by assessing total percentage of body surface area (TBSA) burnt. Individuals who were admitted more than 5 days, with partial or full-thickness burn who developed clinical signs and symptoms of wound infection or pneumonia or septicaemia were included in this study.

Demographic and clinical data including gender, age, degree of burn, TBSA burnt, cause of burn and antibiotic therapy were collected for each participant.

According to the clinical status of the participants, appropriate samples including wound swab, urine and blood samples were taken. The first swab was obtained from deep areas of the burn before any cleaning and transferred to the laboratory by sterile test tube. Blood and urine samples were collected from individuals with signs and symptoms of septicaemia or pneumonia. Blood sampling was repeated three times.

Descriptive statistics were used for demographic and bacteriological profiles of each case; $\chi^{2}$ testing compared the microorganisms sensitivity and resistance patterns to the examined antimicrobial; $\mathrm{p}<0.05$ was considered significant.

\section{Result:}

A total 24, 354 patients were attended in DMCH burn unit from July 2007 to June 2008, of which 2376 (198/ month) acute burn patients were admitted; 1613 (67.88\%) patients were discharged with or without some residual deformity; 547 (23.02\%) patients were expired; $557(23.56 \%)$ patients leave the hospital with or without consent of the authority. (Table-I).

Table-I

\begin{tabular}{|c|c|c|c|c|c|c|c|c|c|}
\hline \multicolumn{10}{|c|}{ Burn \& Plastic Surgery Unit } \\
\hline \multicolumn{10}{|c|}{ Burn patients hospital outcome and pattern : } \\
\hline \multirow[t]{2}{*}{ Month } & \multirow{2}{*}{$\begin{array}{l}\text { Total Patients } \\
\text { Attended } \\
\text { Emergency } \\
\text { \& OPD }\end{array}$} & \multicolumn{3}{|c|}{ Total Pateints attended } & \multirow[b]{2}{*}{$\begin{array}{c}\text { Chemical } \\
\text { Burn }\end{array}$} & \multirow{2}{*}{$\begin{array}{c}\text { Total } \\
\text { Patients } \\
\text { admitted }\end{array}$} & \multirow{2}{*}{$\begin{array}{c}\text { Discharged } \\
(\%)\end{array}$} & \multirow{2}{*}{$\begin{array}{c}\text { DORB \& } \\
\text { Absconded }\end{array}$} & \multirow{2}{*}{$\begin{array}{c}\text { Death } \\
\text { (\%) }\end{array}$} \\
\hline & & $\begin{array}{c}\text { Flame } \\
\text { Burn }\end{array}$ & $\begin{array}{l}\text { Scald } \\
\text { Burn }\end{array}$ & $\begin{array}{c}\text { Electric } \\
\text { Burn }\end{array}$ & & & & & \\
\hline July’07 & 1496 & 90 & 90 & 65 & 06 & 95 & 97 & 17 & 24 \\
\hline August’07 & 1829 & 145 & 137 & 10 & 04 & 60 & 87 & 06 & 24 \\
\hline September’07 & 1487 & 132 & 86 & 39 & 04 & 72 & 104 & 14 & 31 \\
\hline October’07 & 1477 & 93 & 49 & 37 & 05 & 80 & 134 & 31 & 35 \\
\hline November’07 & 1731 & 85 & 87 & 74 & 02 & 245 & 122 & 21 & 34 \\
\hline December’07 & 1833 & 112 & 96 & 68 & 07 & 317 & 207 & 54 & 51 \\
\hline January’08 & 2774 & 90 & 90 & 65 & 06 & 260 & 136 & 105 & 83 \\
\hline February’08 & 3348 & 145 & 137 & 10 & 04 & 314 & 128 & 96 & 89 \\
\hline March’08 & 3351 & 132 & 86 & 39 & 04 & 274 & 114 & 65 & 62 \\
\hline April’08 & 1537 & 93 & 49 & 37 & 05 & 221 & 171 & 65 & 41 \\
\hline May’08 & 1552 & 89 & 47 & 40 & 03 & 219 & 161 & 41 & 43 \\
\hline June’08 & 1939 & 88 & 50 & 49 & 04 & 219 & 152 & 45 & 30 \\
\hline Total & 24354 & 1294 & 1004 & 533 & 54 & 2376 & $\begin{array}{c}1613 \\
(67.88 \%)\end{array}$ & $\begin{array}{c}550 \\
(23.56 \%)\end{array}$ & 547 \\
\hline
\end{tabular}


A total 112 people were included in this study. Their characterstics including gender, distribution of age, cause of burn, and TBSA burnt are presented in Table 2. Nearly $50 \%$ of the participant were aged 11 to 30 yreas. The most common type of burn was flame burn and females were the common victims.

Bacterial isolate were found in 104 (92.85\%) samples and only eight (08) swabs were sterile 7(14\%). Pseudomonas species was the commonest pathogen isolated (46.42\%) followed by proteus species (21.4\%), Klebsiella species (19.6\%), Providencia (19.6\%), E.coli (14.2\%), Acinetobacter (12.5\%) and Staphylococcus aureus (7.1\%). Multiple organism were found in 38 samples (33.92\%), None of the 5 blood sampls contained them. Bacterial isolate were found in only in
9 urine samples (8.03\%) of which pseudomonas species was the commonest (3.57\%), as shown in Table-III.

Antibiogram of Pseudomonas Aeruginosa and Proteus species to 10 antimicrobial agents including carbapenems (Imipenems), Cephalosporins, fluoroquinolones, aminoglycosides and netilmicin are presented in Table-4. The most effective agent against P. aeroginosa was Imipenem (92.30\%). After that, Amikacin and ceftazidime were the most effective agents at $53.80 \%$ and $38.46 \%$ respectively. Most isolates of P.aeroginosa were resistant to ampicillin (100\%), cephalexin (96.15\%), cefixime (92.30\%) and ceftriaxone (88.46), 100\% bacterial isolates of Proteus spp. were sensitive to imipenem, then amikacin 58.33\%; they are highly resistant to cephalosporins (nearly 100\%) and ciprofloxacin (83.33\%).

\section{Table-II}

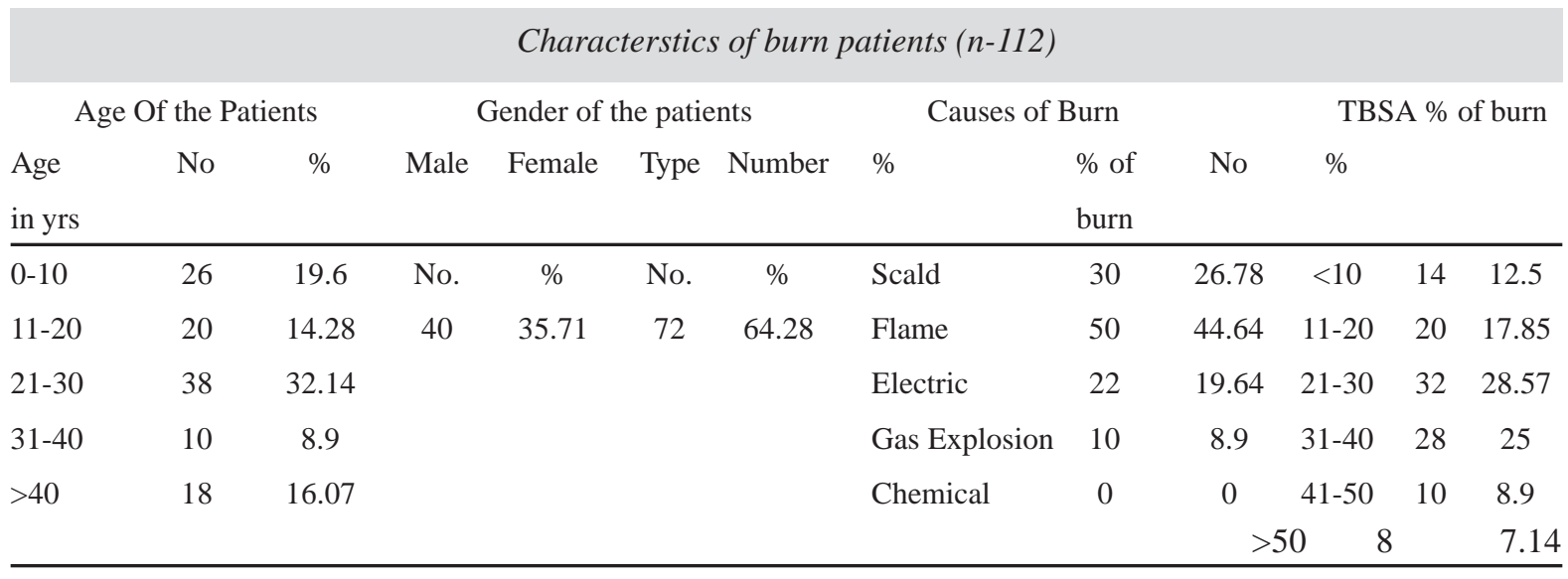

TBSA = Total Burn Surface Area

Table-III

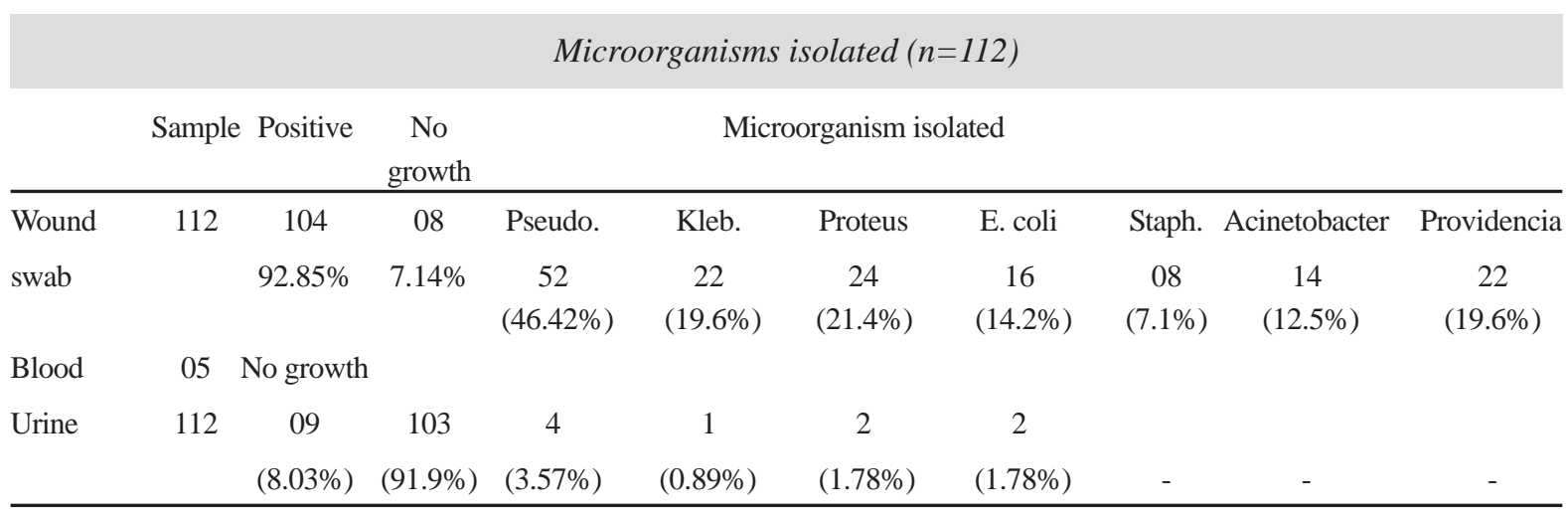

Combined growth — 38 (33.92\%) 


\section{Table-4a}

\begin{tabular}{lccc}
\multicolumn{4}{c}{ Antibiogram for Pseudomonas spp. $(n=52)}$. \\
Antibiotic & Sensitive & Intermediate & Resistance \\
\hline Imipenem & $48(92.30 \%)$ & - & $4(7.6 \%)$ \\
Ciprofloxacin & $6(11.3 \%)$ & - & $46(88.46 \%)$ \\
Amikacin & $28(53.8 \%)$ & $2(3 . .8 \%)$ & $22(42.33 \%)$ \\
Gentamycin & $6(11.53)$ & $2(3.8 \%)$ & $44(84.61 \%)$ \\
Ceftazidime & $20(38.46 \%)$ & $2(3.8 \%)$ & $30(57.69 \%)$ \\
Ceftriaxone & $2(3.8 \%)$ & $4(7.6 \%)$ & $46(88.46 \%)$ \\
Cefixime & $4(7.6 \%)$ & - & $48(92.30 \%)$ \\
Cephalexin & $2(3.8 \%)$ & - & $50(96.15 \%)$ \\
Ampicilin & - & - & $52(100 \%)$ \\
Netilmicin & $16(30.76 \%)$ & - & $36(69.23 \%)$ \\
\hline
\end{tabular}

Table-4b

\begin{tabular}{lccc}
\multicolumn{4}{c}{ Antibiogram for Proteus spp. $(n=24)}$. \\
Antibiotic & Sensitive & Intermediate & Resistance \\
\hline Imipenem & $24(100 \%)$ & - & - \\
Ciprofloxacin & - & $4(16.66 \%)$ & $20(83.33 \%)$ \\
Amikacin & $14(58.33 \%)$ & $2(8.3 \%)$ & $8(33.33 \%)$ \\
Gentamycin & $4(16.66 \%)$ & - & $20(83.33 \%)$ \\
Ceftazidime & $8(33.33 \%)$ & - & $16(66.66 \%)$ \\
Ceftriaxone & $2(8.3 \%)$ & $2(8.3 \%)$ & $20(83.33 \%)$ \\
Cefixime & - & - & $24(100 \%)$ \\
Cephalexin & - & - & $24(100 \%)$ \\
Ampicilin & - & - & $24(100 \%)$ \\
Netilmicin & $8(33.33 \%)$ & - & $16(66.66 \%)$ \\
\hline
\end{tabular}

\section{Discussion:}

Burn patients constitute a subset of patients particularly prone to infection. In the present study the most commonly isolated organisms from burn patients were Pseudomonas species followed by Proteus spp. and Klebsiella spp. and the high resistance rate of $\mathrm{P}$. aeruginosa to common anti Pseudomonas agents. Compared with other studies, it was highly corresponds with the study of G. Khorasania et. al ${ }^{2}$. Like our study Agnihotri et $\mathrm{al}^{11}$ reported that $96 \%$ of swab were positive and $\mathrm{P}$ aeruginosa was found to be the most common isolates (59\%). These results contrast to the study of Mehta Manjula et $\mathrm{al}^{12}$. there was high incidence of Staph aureus isolation next to Pseudomonas. They also found a changing trend in burn bacteriology, it was decreased for Pseudomonas spp. Staph. aureus and Proteus to increase for Klebsiella species. The prevalance of Staph. aureus was very low in our study (only 7.1\%). Another significant difference of our study results to the other studies is that the prevalance of Acinetobacter spp. is very low (12.5\%). There was significant rise in the isolation rate of Acinetobacter spp. over the last five to eight years as stated by Sengupta et $\mathrm{al}^{13}$. Acinetobacter spp. are emerging as an important cause of nosocomial infection in burn units. There are a number of factors which may contribute to this increase like its presence as a normal skin commensal and its easy spread due to multi drug resistance in a hospital settings.

G Khorasani et $\mathrm{al}^{2}$ found high prevelance of Citrobacter freundii in their study and they found citrobacter in all clinical samples except blood.

The high prevelance of P.aeruginosa is in agreement with other studies $2,11,12,13,14$ and may be explained by the fact that this opportunistic microorganism grows mainly in moist body areas, such as burn wounds ${ }^{15}$ and also by prolonged hospital stay and the administration of broad spectrum antibiotics in burn cases. A burn represents a site susceptible to opportunistic colonisation. The situation of burn victims with $P$. aeruginosa infection is particularly problematic, since this organism is inherently resistant to many drugs and is able to acquire resistance to all effective antimicrobial drugs. ${ }^{16}$ The change in the pattern of bacterial resistance in the burn unit has importance both for clinical settings and epidemiological purpose. We saw a significantly high percenatge of resistance among gram-negative bacilli to aminoglycosides like gentamicin and amikacin, ciprofloxacin, amoxicillin, cefotaxime' and ceftriaxone. This alarming trend was seen for both Enterobacteriaceae group and Pseudomonas spp. as seen in the study of Mehta et $\mathrm{al}^{12}$. A similar report of multidrug resistant gram-negative bacilli was also reported by Singh et $a^{17}$. In comparison, imipenem and combination of drugs were found to be effective. This could be due to the reason that these are reserve drugs and used as last options for multi drug resistant bacteria in our hospital settings. Such high antimicrobial resistance is probably promoted due to selective pressure exerted by an bacteria due to numerous reasons like non adherece to hospital; antibiotic policy and excessive and indiscriminate use of broad spectrum antibiotics. 
These multidrug resistant strains establish themselves in the hospital environment in areas like sinks, taps, railing, mattress, toilets and thereby spread from one patient to another. The implementation of a strict infection control strategy with a more rational use of antibiotics, including topical formulations and antimicrobial rotation, has been proposed to prevent the high incidence of multi-drug resistant strains of microorganism, particularly of P. aeruginosa in burn units $^{18}$.

Conclusion:

Routine microbiological surveillance and careful in vitro testing prior to antibiotic use and strict adherence to hospital antibiotic policy may help in the prevention and treatment of multi-drug resistant pathogens in burn infection.

\section{References :}

1. Jesse B. Hall, MD. Grocery A. Schmidt, MD. Lawrance D.H. Wood, MD. PH; et al. Burns:resuscitation phase (Day 2 to Day 6), Principle of Critical care; $2^{\text {nd }}$ ed. 1998;1437-1442.

2. G.Khorasania, E. Salehifarb and G Eslamib; Profile of microorganism and antimicrobial resistance as tertiary care refferal burn center in Iran; Science Direct-Burn; Accepted 11 Dec.2007; Available online 2 April 2008.

3. Edward s-Jones V, Greenwood JE, Manchester Burns Research Group. What's new in Burn microbiology? JamesLaing Memorial Prize Essay 2000. Burns 2003; 29(1): $15-24$.

4. Vindenes H, Bjerknes R. Microbial colonization of Large wounds. Burns 1995;21:575-9.

5. P.G. Bowler, B.I. Duerden and D.G. Armstrong, Wound microbiology and associated approaches to wound management, Clin Microbiol Rev 2001; 14: 244-269.
6. Krizek T. Local factors influencing incidence of wound sepsis.Symposium on antibiotic prophylaxis and therapy. Contemp Surg 1977;10: 45-50.

7. K.M. Ramakrishnan, V. Jayaraman, K. Ramachandran and T. Mahdivanan, The management of anaerobic infection in extensive burns, Burns 1986, 12: 270-272.

8. Muller C:Burns and the immune network. J Trauma 1979; 19: 880 .

9. J. Vrankova and V. Adamkova, Bacteriological monitoring after burn injury, Acta Chir Plast 2004; 46: 48-50.

10. Ananthakrishanan AN, Kanungo R, Kumar K, Badrinath S. Detection of extended spectrum beta Lactamase producers among surgical wound infections and burn patients in JIPMER. Indian J Med Microbiol 2002; 18: 160-5.

11. N. Agnihotri, V. Gupta and R.M. Joshi, Aerobic bacterial isolates from burn wound infections and their antibiograms a five-year study, Burns 2004; 30: 241-243.

12. Mehta M, Dutta P, Gupta V. Bacterial isolates from burn wound infections and their antibiograms: A eight-year study. Indian J Plast Surg 2007; 40: 25-8

13. Sengupta S, Kumar P, Ciraj AM, Shivananda PG. Acinetobacter baumannii - an emerging nosocomial pathogen in the burns unit. Manipal, India. Burns 2001; 27: $140-4$.

14. A.R. Lari, H.B. Honar and R. Alaghehbandan, Pseudomonas infection in Tohid burn center, Iran, Burns 1998; 24: 637641.

15. W. Song, K.M. Lee, H.J. Kang, D.H. Shin and D.K. Kim, Microbiologic aspects of predominant bacteria isolated from the burn patients in Korea, Burns 2001; 27: 136-139.

16. D.M. Livermore, Multiple mechanisms of antimicrobial resistance in Pseudomonas aeruginosa: our worst nightmare?, Clin Infect Dis 2002; 34: 634-640.

17. Singh NP, Goyal R, Manchanda V, Das S, Kaur Z, Talwar V. Changing Trends in bacteriology of burns in the burns units, Delhi, India. Burns 2003; 29: 129-32.

18. B.A. Cunha, Strategies to control antibiotic resistance, Semin Respir Infect 2002; 17: 250-258. 